\title{
Conjuntura da produção de ovos de codorna no Estado do Pará
}

\author{
Quail egg production situation in the State of Pará \\ Situación de la producción de huevos de codorniz en el Estado de Pará
}

Wânia Mendonça dos Santos

ORCID: https://orcid.org/0000-0001-9598-4855

Universidade Federal do Pará, Brasil

E-mail: wmsan.84@gmail.com

Samara Mendonça dos Santos

ORCID: https://orcid.org/0000-0003-3711-4266

Universidade Federal Rural da Amazônia, Brasil

E-mail: samaraufra2016@gmail.com

Fabrício Khoury Rebello

ORCID: https://orcid.org/0000-0003-2398-4906

Universidade Federal Rural da Amazônia, Brasil

E-mail: fabriciorebello@ hotmail.com

Marcos Antônio Souza dos Santos

ORCID: https://orcid.org/0000-0003-1028-1515

Universidade Federal Rural da Amazônia, Brasil

E-mail: marcos.marituba@gmail.com

Bruno Cabral Soares

ORCID: https://orcid.org/0000-0003-1803-8907

Universidade Federal Rural da Amazônia, Brasil

E-mail: brunocs@veterinario.med.br

João Paulo Borges de Loureiro

ORCID: https://orcid.org/0000-0001-8586-8201

Universidade Federal Rural da Amazônia, Brasil

E-mail: joaopaulo_loureiro@hotmail.com

\begin{abstract}
Resumo
Neste estudo apresenta-se uma conjuntura da produção de ovos de codorna no estado do Pará, a partir de uma análise do período de 2000-2019, utilizando dados secundários de série temporal de produção de ovos e quantitativo de cabeças de codornas, obtidos junto ao Banco de Dados do IBGE. Foram estimados o Quociente Locacional (QL) que indica a especialização de uma região em uma determinada atividade ou setor e o Coeficiente de Gini Locacional (CGL) que identifica a concentração espacial. Os resultados do estudo mostram que no período analisado a mesorregião Metropolitana de Belém perdeu força participativa na produção paraense colocando as mesorregiões Sudeste e Sudoeste Paraense com a maior concentração da produção do estado. Os municípios de Altamira, Paragominas e Santarém se apresentam como os maiores produtores de ovos de codorna do estado do Pará. Apesar disso, a produção de ovos de codorna paraense, nos últimos anos, se apresenta em declínio e redução das microrregiões especializadas, observando-se elevada concentração espacial.
\end{abstract}

Palavras-chave: Coturnicultura; Coturnix coturnix japônica; Agronegócio; Amazônia brasileira.

\begin{abstract}
This study presents an overview of the production of quail eggs in the state of Pará, based on an analysis of production in the period 2000-2019 using secondary data from the time series of egg production and the number of quail heads / beaks obtained with the IBGE Database. The Locational Quotient (LQ) indexes that indicate the specialization of a region in a given activity or sector and the Locational Gini Coefficient (LGC) that identifies the spatial concentration were estimated. The results of the study show that in the period analyzed, the Metropolitan Mesoregion of Belém lost its participatory power in Pará production, placing the Southeast and Southwest Paraense mesoregions with the highest concentration of production in the state. The municipalities of Altamira, Paragominas and Santarém present themselves as the largest producers of quail eggs in the state of Pará. Despite this, the production of quail eggs in Pará, in recent years, has been declining and reducing the specialized micro-regions, high spatial concentration.
\end{abstract}

Keywords: Coturniculture; Coturnix coturnix japonica; Agribusiness; Brazilian amazon.

\section{Resumen}

Este estudio presenta un panorama de la producción de huevos de codorniz en el estado de Pará, basado en un análisis de la producción en el período 2000-2019 utilizando datos secundarios de la serie temporal de producción de huevos y 
el número de cabezas / picos de codorniz obtenidos. con la Base de Datos IBGE. Se estimaron los índices de Cociente de Ubicación (CU) que indican la especialización de una región en una determinada actividad o sector y el Coeficiente de Gini de Ubicación (CGU) que identifica la concentración espacial. Los resultados del estudio muestran que en el período analizado, la Mesorregión Metropolitana de Belém perdió su poder de participación en la producción de Pará, colocando a las mesorregiones Paraense Sudeste y Sudoeste con la mayor concentración de producción en el estado. Los municipios de Altamira, Paragominas y Santarém se presentan como los mayores productores de huevos de codorniz en el estado de Pará. A pesar de ello, la producción de huevos de codorniz en Pará, en los últimos años, ha ido disminuyendo y reduciendo las microrregiones especializadas, alta concentración espacial.

Palabras clave: Coturnicultura; Coturnix coturnix japônica; Agronegocios; Amazonia brasileña.

\section{Introdução}

A avicultura é uma atividade bastante comum no meio rural e de grande importância no agronegócio, principalmente pela comercialização dos ovos. Uma das espécies de aves poedeira utilizada no Brasil é a codorna doméstica (Coturnix coturnix japonica), originaria da Ásia, sendo resultado de vários cruzamentos da espécie selvagem Coturnix coturnix. Porém, é utilizada em menor escala quando comparada à galinha doméstica (Gallus domesticus).

No Brasil, a atividade de coturnicultura teve um importante passo no início de 1989, a partir da implantação do primeiro criatório no Sul do Brasil o que possibilitou o começo de sua exploração comercial (Silva et al., 2011) e posterior a isso, a atividade passou de subsistência para tecnificada com utilização de novas técnicas de produção (Pastore et al., 2012) levando ao desenvolvimento da atividade.

A criação de codornas se torna uma alternativa interessante para pequenos produtores pelo fato de possuir investimento e manutenção de baixo custo em relação às outras criações, utilização de pequena área para instalação e apresentando rápido retorno do investimento, a partir do segundo ano (Silva et al., 2018). Além disso, a atividade contribui para o fortalecimento da economia do agronegócio através da movimentação da cadeia produtiva deste segmento com consequente geração de renda.

De acordo com Matos (2007), a espécie doméstica (Coturnix coturnix japonica) chega a pesar em torno de 150g, tendo sua fase de postura iniciada aos 45 dias de vida e ciclo produtivo de dez meses, possuindo um intervalo de dois meses, sendo o primeiro ano o mais produtivo, podendo atingir até 300 ovos por ave no ano.

Os estados do Espírito Santo e São Paulo, lideram o ranking dos maiores produtores brasileiros, sendo o estado do Pará o $22^{\circ}$ no ranking nacional e $4^{\circ}$ da região Norte na produção de ovos de codorna.

A produção de carnes de codorna no Brasil vem crescendo ao longo das últimas décadas, em decorrência do aumento do interesse dos consumidores (Miranda et al., 2013). No entanto, o consumo nacional se concentra nos ovos (Pasquetti et al., 2011), que somente nos últimos 20 anos apresentou crescimento anual de 8,09\%. O ovo é um alimento completo e equilibrado, rico em proteínas e baixo teor de gordura, tendo na porção lipídica as maiores concentrações de ácidos graxos insaturados (Sarcinelli et al., 2007). Possui alto valor biológico e baixo preço relativo para aquisição (Carvalho et al., 2007; Mota et al., 2017).

De acordo com Sarcinelli et al. (2007), a composição química do ovo de codorna se assemelha ao de galinha, como no caso da proteína. Porém, o ovo de codorna possui alguns componentes em maiores quantidades do que o ovo de galinha, como as vitaminas A, B1 e B3, cálcio, fósforo e zinco (Taco, 2011). Quanto ao tamanho e peso, o ovo de codorna possui, em média $11 \mathrm{~g}$, isso representa de 8 a 10\% do peso corporal da ave, já para o ovo de galinha essa proporção é de apenas 3\% (Mendonça, 2020).

Diante dessas características da atividade e de seu potencial de comercialização, o mercado do ovo de codorna vem crescendo no Brasil e, desta forma, estimulando a realização de estudos sobre a coturnicultura, principalmente nas áreas de melhoramento genético, manejo, nutrição e produção das aves e na tecnificação da produção de ovos com o intuito de aumentar a produtividade. 
Neste estudo, avalia-se a conjuntura da produção de ovos de codorna no contexto paraense, identificando as microrregiões especializadas e a concentração espacial da atividade no estado do Pará, como forma de subsidiar com informações que auxiliem na execução de políticas públicas e iniciativas empresariais que impulsionem o crescimento e desenvolvimento da atividade.

\section{Metodologia}

\section{1. Área de estudo}

O estado do Pará, localizado na Região Norte do Brasil, ocupa uma área de $1.245 .870 \mathrm{~km}^{2}$, sendo geograficamente dividido em seis mesorregiões, 22 microrregiões e 144 municípios, com população estimada de 8,7 milhões de habitantes no ano de 2020 (Instituto Brasileiro de Geografia e Estatística (IBGE), 2020).

Há existência de três climas predominantes: Af, Am e Aw pertencentes ao clima tropical chuvoso (Kottek et al., 2006). Possui condições ambientais favoráveis à produção agropecuária com cadeias produtivas do agronegócio que impulsionam a economia regional. Dentre as cadeias produtivas existentes no estado do Pará, a avicultura comercial integra parte da economia de 28 municípios do estado (Agência de Defesa Agropecuária do Estado do Pará (ADEPARÁ), 2020), tendo sua produção concentrada na Região Metropolitana de Belém, em parte do Nordeste Paraense e no Baixo Amazonas. A coturnicultura vem se inserindo na avicultura industrial como um segmento com potencial de produção e desenvolvimento econômico para o agronegócio paraense.

\subsection{Base da coleta de dados e análises}

A pesquisa foi realizada seguindo abordagem exploratória e quantitativa, partir da análise de dados secundários de séries temporais. De acordo com Zanella (2013), dados secundários são aqueles que já foram coletados, tabulados, ordenados, bem como analisados. Os dados foram obtidos junto ao Censo Agropecuário e na Pesquisa Pecuária Municipal, produzidas pelo Instituto Brasileiro de Geografia e Estatística (IBGE, 2020), em que se obtiveram informações da produção e valor da produção de ovos de codorna para os anos de 2000 a 2019.

Para análise das microrregiões especializadas e concentração espacial da produção de ovos de codorna, foram estimados o Quociente Locacional (QL) e o Gini Locacional (GL). Sendo que o QL visa comparar a participação percentual de um setor ou atividade em um município ou região com a participação percentual no total da economia estadual ou nacional (Haddad, 1989). O GL, por sua vez, identifica quão concentrada é uma determinada atividade em uma região. Os dados utilizados para calcular o índice de QL foram os valores da produção de ovos de codorna e da produção agropecuária em cada microrregião e o valor das mesmas para o estado do Pará, obtidos nos Censos Agropecuários de 2006 e 2017. A fórmula utilizada foi a seguinte (Haddad, 1989):

$$
Q L=\frac{V P O_{i j} / V P A_{j}}{V P O_{P A} / V P A_{P A}}
$$

Onde:

$V P O_{j}=$ corresponde ao valor da produção de ovos de codorna na microrregião $j$;

$V P A_{j}=$ corresponde ao valor da produção agropecuária na microrregião $j$;

$V P O_{P A}=$ corresponde ao valor da produção de ovos de codorna no estado do Pará; e

$V P A_{P A}=$ corresponde ao valor da produção agropecuária no estado do Pará.

Foi utilizado como valor de referência o $\mathrm{QL} \geq 1$ que significa que determinada região é especializada na atividade (Monasterio \& Cavalcante, 2011), ou seja, identifica as microrregiões do estado do Pará onde a atividade de produção de ovos 
de codorna se destaca dentro da produção agropecuária.

Para calcular o Gini Locacional (GL), utilizaram-se os valores da produção de ovos de codorna nas microrregiões e no estado do Pará. Este tipo de análise é bastante utilizado para identificar a distribuição de renda, porém, pode ser facilmente utilizado em análises econômicas diversas, como no caso de atividades agropecuárias.

É utilizada uma faixa de referência para o GL, que varia de 0 a 1, portanto, quanto mais próximo de 1 estiver o GL, significa maior concentração espacial de uma atividade. Para tanto, o oposto é verdadeiro, ou seja, quanto mais próximo de 0 for o GL, significa que há uma melhor distribuição da atividade na região e, quando for igual a 0 , a atividade é distribuída uniformemente. Para o controle, será utilizado como referência o GL acima de 0,5 como identificação de maior concentração e menor que 0,5 para maior distribuição espacial da atividade (Suzigan et al., 2004). Foram utilizados os valores da produção de ovos de codorna dos anos de 2000, 2010 e 2019 obtidos na Pesquisa Pecuária Municipal do Sistema IBGE de Recuperação Automática. No cálculo do GL utilizou-se a seguinte fórmula proposta por Brown (1994):

$$
G L=1-\sum_{i=0}^{k-1}\left(Y_{i+1}+Y_{i}\right)\left(X_{i+1}-X_{i}\right)
$$

Sendo:

Yi = participação do Valor da Produção de ovos de codorna na economia agropecuária da região $i$; $\mathrm{Xi}=$ participação do Valor da Produção Agropecuária da região $i$ na economia setorial do estado.

Tais indicadores contribuem na identificação da distribuição espacial e especializações regionais, permitindo verificar o movimento de deslocamento das atividades econômicas (Suzigan et al., 2003).

Para a análise de dados utilizou-se o software Microsoft@ Office Excel, versão 2013.

\section{Resultados e Discussão}

De acordo com dados do IBGE (2020), a produção brasileira de ovos de codorna alcançou, no ano de 2019, 315 milhões de dúzias de ovos. A região Sudeste concentra mais da metade da produção brasileira, representando 67,32\% do total nacional, seguida das regiões Sul (15,29\%), Nordeste $(12,72 \%)$, Centro-Oeste $(4,19 \%)$ e Norte $(0,47 \%)$.

$\mathrm{Na}$ Figura 1, são apresentados os estados produtores de ovos de codorna no Brasil em ordem decrescentes de produção.

São Paulo ocupava a liderança na produção nacional de ovos de codorna até o ano de 2018. Em 2000, participava com $50,74 \%$ da produção nacional, passando para 23,57\% em 2019, quando perdeu a liderança para o estado do Espírito Santo que passou de 4,25\% de participação no total nacional, em 2000, para 23,88\% em 2019. O município de Santa Maria de Jetibá (ES) é o maior produtor nacional. Os estados de Minas Gerais, Santa Catarina e Ceará, estão entre os cinco maiores produtores de ovos de codorna do Brasil. Já o estado do Pará ocupa a $22^{\mathrm{a}}$ posição no cenário nacional e o estado do Amapá ocupa a última posição, sem representação de produção. 
Figura 1. Produção de ovos de codorna nos estados brasileiros no ano de 2019.

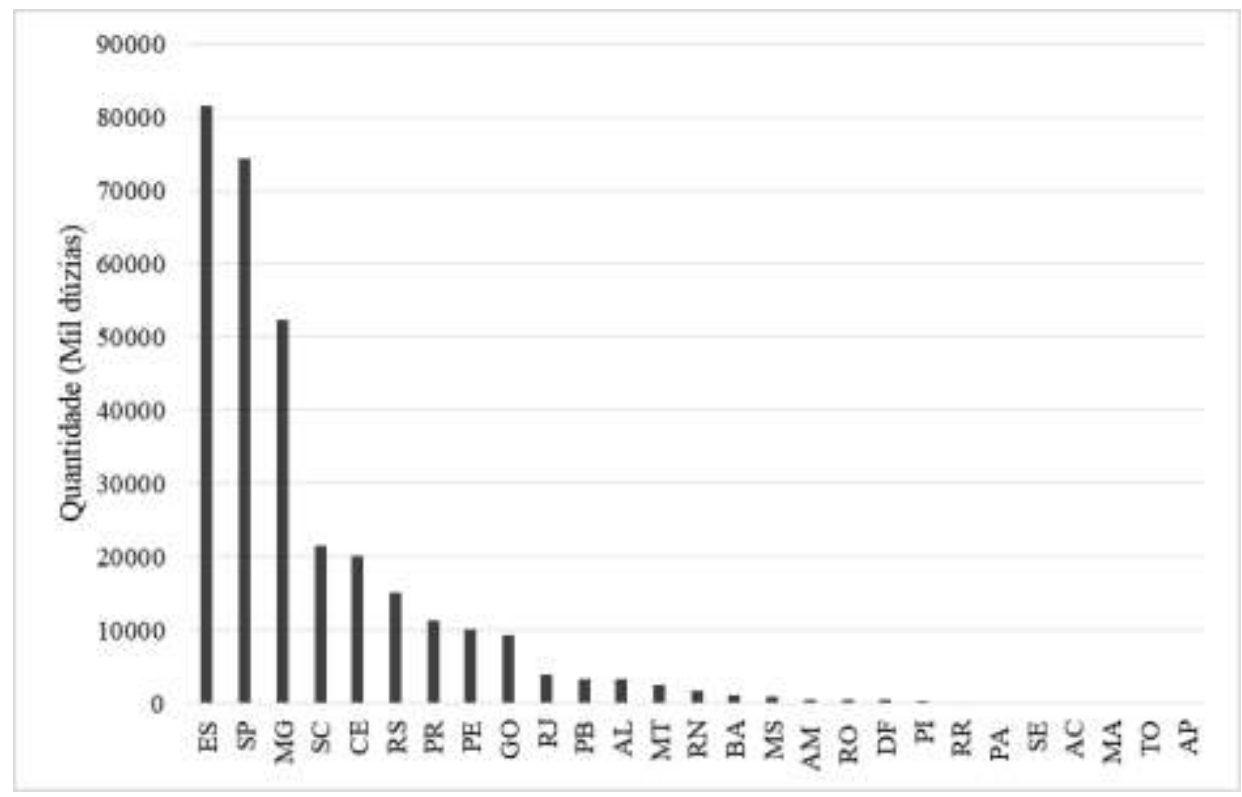

Fonte: Dados da pesquisa.

Entre os anos de 2018 e 2019, a região Nordeste apresentou o maior incremento na produção de ovos de codorna $(45,55 \%)$, isso se deve aos estados do Ceará e Sergipe que tiveram altas de $142,48 \%$ e 91,72\%, respectivamente. As regiões Norte e Sudeste, registraram altas de $15,46 \%$ e 4,38\%. O percentual de aumento da produção de ovos de codorna da região Norte no ano de 2019 em comparação com o ano anterior (2018) foram os seguintes: Amazonas (75,00\%), Roraima (18,48\%), Rondônia (3,65\%), Acre (2,70\%), Amapá (0,00\%), Pará (-9,17\%) e Tocantins $(-31,62 \%)$.

A Tabela 1 apresenta o percentual de participação dos estados da região Norte na produção total nos últimos cinco $\operatorname{anos}(2015$ a 2019).

Tabela 1. Participação percentual dos estados da região Norte na produção de ovos de codorna, 2015 a 2019.

\begin{tabular}{|c|c|c|c|c|c|c|c|c|c|c|}
\hline \multirow[b]{2}{*}{ Estados } & \multicolumn{2}{|c|}{2015} & \multicolumn{2}{|c|}{2016} & \multicolumn{2}{|c|}{2017} & \multicolumn{2}{|c|}{2018} & \multicolumn{2}{|c|}{2019} \\
\hline & $\begin{array}{c}\text { Mil } \\
\text { dúzias }\end{array}$ & $\%$ & $\begin{array}{c}\text { Mil } \\
\text { dúzias }\end{array}$ & $\%$ & $\begin{array}{c}\text { Mil } \\
\text { dúzias }\end{array}$ & $\%$ & $\begin{array}{c}\text { Mil } \\
\text { dúzias }\end{array}$ & $\%$ & $\begin{array}{c}\text { Mil } \\
\text { dúzias }\end{array}$ & $\%$ \\
\hline Amazonas & 394 & 19,65 & 438 & 25,07 & 453 & 30,34 & 341 & 26,50 & 537 & 36,14 \\
\hline Rondônia & 539 & 26,88 & 512 & 29,31 & 510 & 34,16 & 522 & 40,56 & 530 & 35,67 \\
\hline Roraima & 520 & 25,94 & 520 & 29,77 & 137 & 9,18 & 150 & 11,66 & 170 & 11,44 \\
\hline Pará & 452 & 22,54 & 206 & 11,79 & 171 & 11,45 & 149 & 11,58 & 127 & 8,55 \\
\hline Acre & 100 & 4,99 & 72 & 4,12 & 178 & 11,92 & 84 & 6,53 & 87 & 5,85 \\
\hline Tocantins & 0 & - & 0 & - & 43 & 2,88 & 41 & 3,19 & 35 & 2,36 \\
\hline Amapá & 0 & - & 0 & - & 0 & - & 0 & - & 0 & - \\
\hline Total da região Norte & 2.005 & - & 1.747 & - & 1.493 & - & 1.287 & - & 1.486 & - \\
\hline
\end{tabular}

Fonte: Dados da pesquisa.

Os estados do Amazonas e Rondônia, juntos, representam 71,81\% do total no ano de 2019 e o Pará se encontra na $4^{\mathrm{a}}$ posição do ranking regional, com participação de $8,55 \%$ no mesmo ano.

Vale ressaltar que o estado do Pará era o maior produtor de ovos de codorna da região Norte entre os anos de 2000 a 2013, declinando na produção a partir do ano de 2016. Em 2014, Roraima, que até então não apresentava registro de produção, 
assumiu a representatividade da região Norte com o quantitativo de 630 mil dúzias de ovos, entretanto, nos anos seguintes declinou, apresentando participação de 11,44\% no total da região Norte no ano de 2019. Em Rondônia, o município de Porto Velho concentra toda a produção de ovos de codorna do estado. A produção de ovos de codorna se restringe apenas ao município de Porto Velho que mostra quantitativo de produção similar à produção total do estado do Amazonas.

Em estudo realizado no Pará, Silva et al. (2019), apontam que o estado é o segundo maior produtor de ovos de galinha da região Norte, tendo o Amazonas como o maior produtor. De acordo com Cruz et al. (2016), no estado do Amazonas, o segmento de aves de postura sofreu considerável mudança produtiva a partir dos anos de 1990, seguindo exemplos de outras regiões do país, adotando modelos tecnológicos e profissionalização da cadeia produtiva. É provável que essas mudanças tenham se expandido para a coturnicultura, colocando o estado em um patamar importante na produção de ovos de codorna.

A Figura 2 mostra a evolução da produção de ovos de codorna no Estado do Pará e na Região Norte com base na série histórica dos anos de 2000 a 2019.

Figura 2. Produção de ovos (mil dúzias) no estado do Pará e região Norte (2000 a 2019).

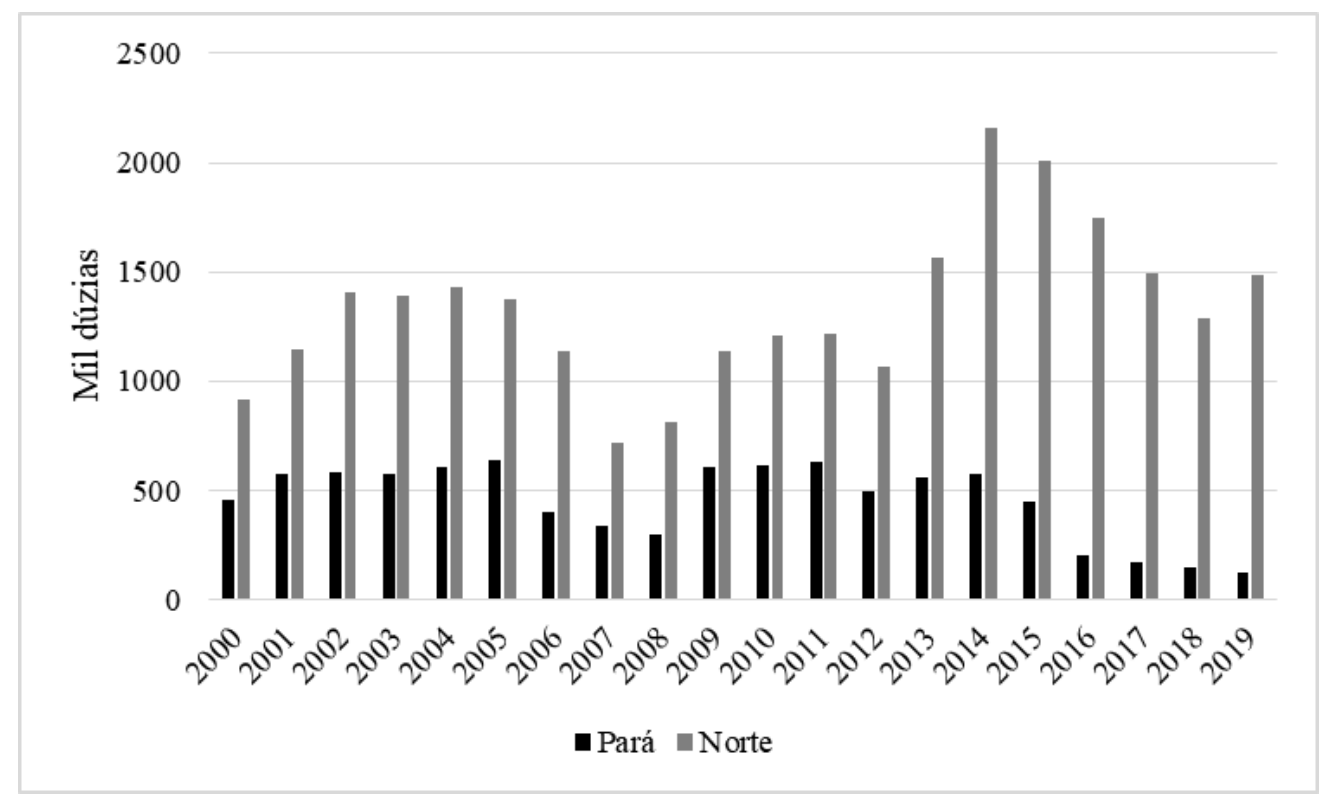

Fonte: Dados da pesquisa.

De acordo com a Figura 2, a produção de ovos de codorna apresentou oscilações no quantitativo produzido ao longo do período analisado. Observa-se a ocorrência de dois momentos de queda na produção paraense. Uma diminuição entre os anos de 2006 e 2008, com elevação e estabilização até o ano de 2015, com queda no ano seguinte, mantendo esse comportamento baixo de produção até o ano de 2019. Esse comportamento pode estar relacionado com o aumento da produção paraense de ovos de galinha, que de acordo com dados da Produção Pecuária Municipal do IBGE (2020), entre os anos de 2006 e 2019, houve crescimento expressivo da produção de ovos de galinha.

Entre as mesorregiões, conforme a Figura 3, observa-se que até o ano de 2015 a mesorregião Metropolitana de Belém era a maior produtora de ovos de codorna no estado Pará, apresentando duas quedas significativas ao longo do período, sendo uma entre os anos de 2005 e 2008 e outra em 2015, enquanto que as demais mesorregiões mantiveram tendência de crescimento. 
Figura 3. Evolução da produção de ovos de codorna nas mesorregiões do Estado do Pará (2000 a 2019).

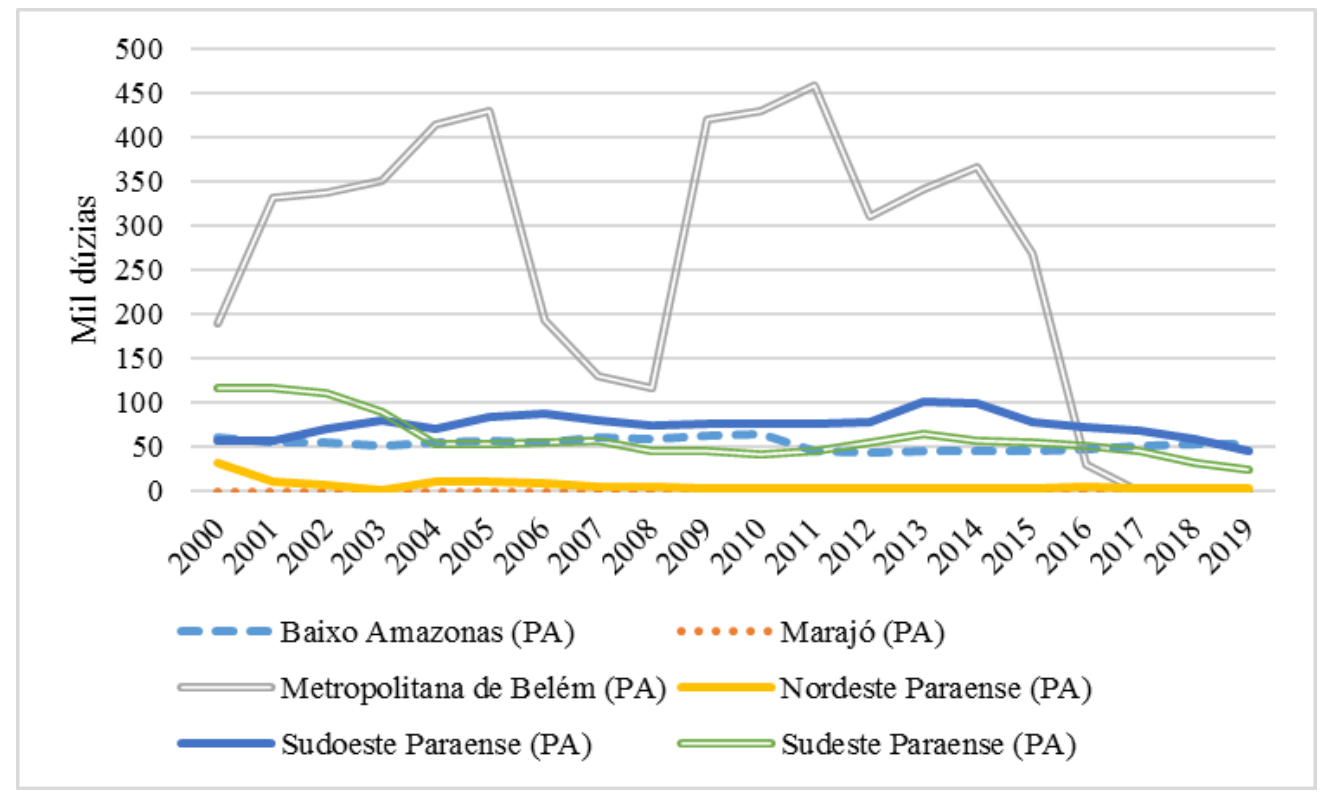

Fonte: Dados da pesquisa.

O período de queda a partir do ano de 2015 coincide com o período em que os municípios de Ananindeua e Santa Isabel do Pará, antes tidos como impulsionadores da produção de ovos de codorna, não mostraram registros de produção e com isso tornando a curva de produção de ovos de codorna da mesorregião Metropolitana de Belém, declinante, ao passo que Santa Isabel do Pará apresentou aumento da produção de ovos de galinha de 3,89\% ao ano entre os anos de 2015 e 2019. Assim, supõe-se que a produção de ovos de codorna não suportou a concorrência de mercado com os ovos de galinha nesses municípios.

Os municípios de Altamira, Paragominas e Santarém representaram, no ano de 2019, 81,89\% do total da produção de ovos de codorna do estado do Pará. É válido destacar que os municípios de Paragominas e Santarém são os maiores detentores da produção de grãos, com destaque para soja e milho. Haja vista que tais grãos são componentes para produção de rações balanceadas para as aves e a presença de estabelecimentos fabricantes de produtos para alimentação animal nesses locais, tornam-se atrativos para a atividade pelo fato de reduzir custos de importação desses insumos.

O município de Santarém é responsável pela atual representatividade da produção de ovos de codorna da mesorregião do Baixo Amazonas. Os municípios de Ananindeua e Santa Isabel do Pará, pertencentes à mesorregião Metropolitana de Belém, representavam mais da metade da produção do Estado entre os anos de 2000 e 2015, o que explica a queda brusca da produção nesta mesorregião a partir do ano de 2015.

Na Figura 4, estão expostas as microrregiões especializadas economicamente na produção de ovos de codorna com seus respectivos Quocientes Locacionais (QL). 
Figura 4. Índice de Quociente Locacional das microrregiões especializadas na produção de ovos de codorna (2006 e 2017).

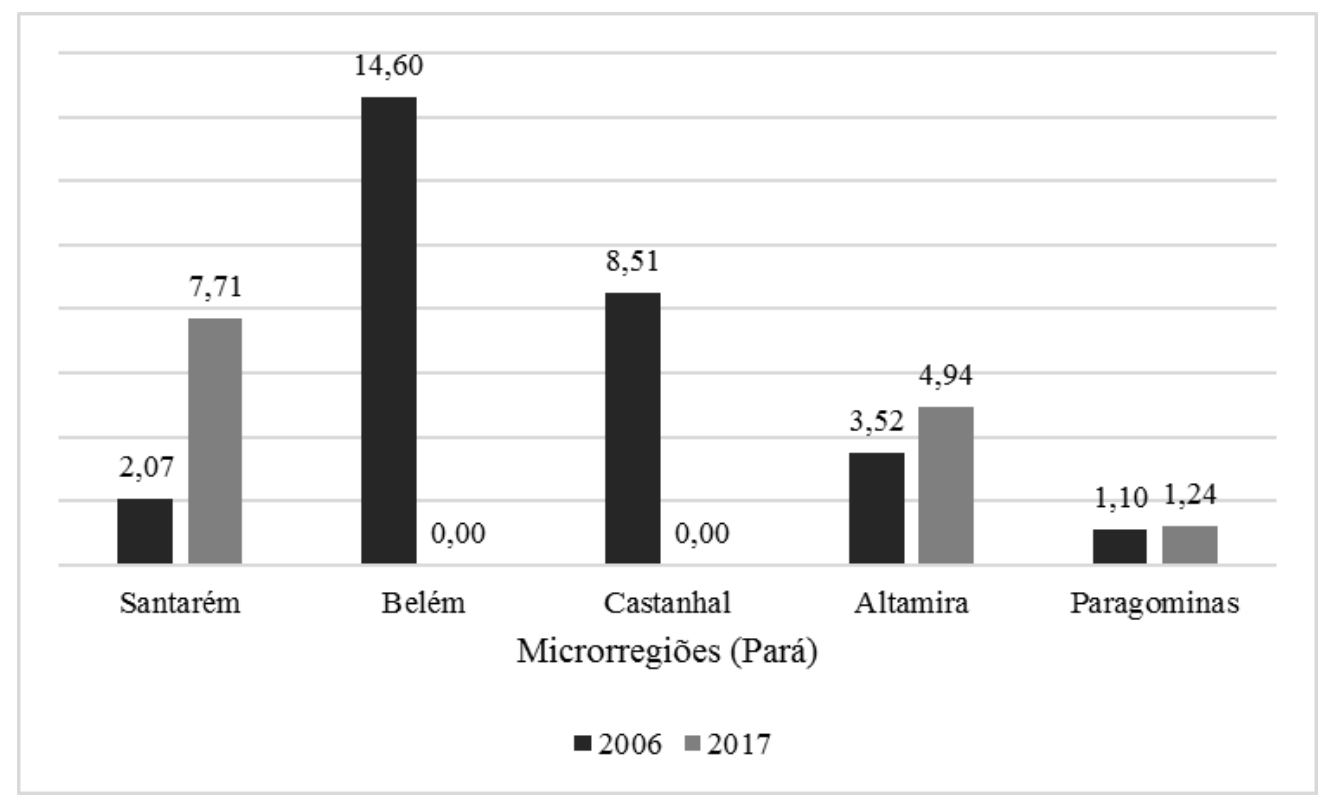

Fonte: Dados da pesquisa.

No ano de 2006, haviam cinco microrregiões especializadas, sendo elas: Santarém, Belém, Castanhal, Altamira e Paragominas. Em 2017, no entanto, esse cenário mudou, apresentando uma redução no quantitativo de microrregião especializada economicamente, passando de cinco para três: Santarém, Altamira e Paragominas.

Estes resultados permitem inferir que as microrregiões que se mantiveram especializadas apresentaram tal comportamento devido à sua localização geográfica coincidir com os polos agrícolas de grãos, dotando-as de vantagem competitiva por conta da oferta de ração com menor preço e, desta forma, propiciar a redução no custo de produção dos ovos. Outro aspecto relevante é que esses municípios são centros de consumo significativo na economia paraense e eixos comerciais com rotas regulares de transporte para escoar a produção, tanto em seu entorno como regionalmente.

Quanto à concentração espacial, a Figura 5 apresenta o grau de concentração da produção de ovos de codorna aferidos pelo Gini Locacional (GL). Observa-se leve queda no ano de 2010 com seguida elevação em 2019. Logo, pode-se afirmar que está ocorrendo um aumento da concentração espacial da produção (desigualdade) com GL>0,5, mostrando o índice atual de GL de 0,80 .

Os resultados mostram que ao mesmo tempo em que ocorreu a redução das microrregiões especializadas houve um aumento na concentração espacial da produção de ovos de codorna. Ottonelli e Grings (2017), em estudo realizado no Rio Grande do Sul, mostraram que o aumento no número de microrregiões especializadas na produção de arroz ocasionou a redução da centralização espacial da atividade, ou seja, houve uma distribuição espacial da atividade na região. Para Marion Filho et al. (2011), o resultado foi diferente ao analisarem a pecuária leiteira no Paraná, pois ocorreu tanto o aumento da especialização quanto a concentração espacial da produção. 
Figura 5. Coeficiente de Gini Locacional no estado do Pará (2000, 2010 e 2019).

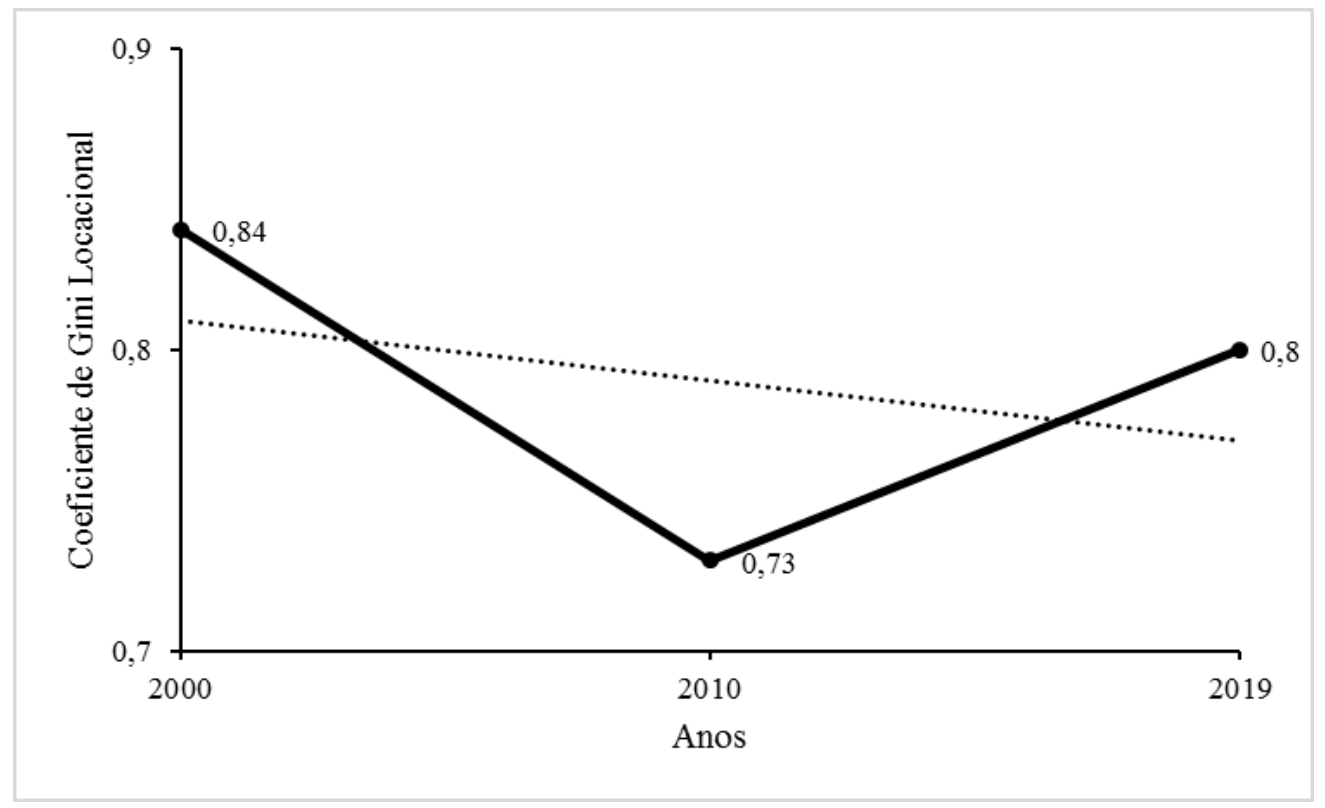

Fonte: Dados da pesquisa.

A identificação das regiões com especialização produtiva pode ser utilizada como uma proxy do nível de desenvolvimento de um determinado setor produtivo, sendo que há vantagens competitivas ao setor, conforme o aumento do nível de especialização (Monasterio \& Cavalcante, 2011). De acordo com Marion Filho et al. (2015), a maior concentração espacial de uma atividade apresenta dois pontos de vista econômico, para a sociedade e para a região, ou seja, quando ocorre a aceleração da produtividade e maior especialização, é benéfica para a sociedade, porém, quando fica restrita a uma região torna o preço de comercialização do produto mais elevado, beneficiando os produtores devido ao aumento do poder de negociação.

\section{Conclusão}

O estado do Pará é o quarto maior produtor de ovos de codorna da região Norte do Brasil. A mesorregião Metropolitana de Belém perdeu força participativa na produção do estado do Pará colocando as mesorregiões Sudeste e Sudoeste Paraense com a maior concentração da produção estadual. Os municípios de Altamira, Paragominas e Santarém são, atualmente, os maiores produtores de ovos de codorna do estado do Pará.

Atualmente, a produção de ovos de codorna paraense se apresenta em declínio e redução das microrregiões especializadas. As microrregiões de Altamira, Santarém e Paragominas se apresentam como especializadas na produção e a concentração espacial se configura como elevada.

\section{Referências}

Agência de Defesa Agropecuária do Estado do Pará. (2020). Adepará colabora para o desenvolvimento da avicultura do Estado. http://www.adepara.pa.gov.br/artigos/adepar\%C3\%A1-colabora-para-o-desenvolvimento-da-avicultura-do-estado

Brown, M. C. (1994). Using Gini-style indices to evaluate the spatial patterns of health practitioners: theoretical considerations and an application based on Alberta data. Social Science \& medicine, 38 (9), 1243-1256. 10.1016/0277-9536(94)90189-9

Carvalho, F. B., Stringhini, J. H., Jardim Filho, R. M., Leandro, N. S. M., Café, M. B., \& Deus, H. A. S. B. (2007). Qualidade interna e de casca para ovos de poedeiras comerciais de diferentes linhagens e idades. Ciência Animal Brasileira, 8(1), 25-30. https://www.revistas.ufg.br/vet/article/view/1155

Cruz, F. G. G., Rufino, J. P. F, Melo, R. D., Feijó, J. C., Damasceno, J. L., \& Costa, A. P. G. C. (2016). Perfil socioeconômico da avicultura no setor primário do estado do Amazonas, Brasil. Revista do Agronegócio e Meio Ambiente, 9(2), 371-391. https://periodicos.unicesumar.edu.br/index.php/rama/article/view/4321 
Haddad, P. R. Medidas de localização e de especialização. In: Haddad, P.R., Ferreira, C. M. C., Boiser, S., \& Andrade, T. A. (Org.) (1989). Economia Regional: teorias e métodos de análise. Fortaleza: BNB-ETENE, 694p.

Instituto Brasileiro de Geografia e Estatística. (2020). Cidades e Estados. https://www.ibge.gov.br/cidades-e-estados/pa.html

Instituto Brasileiro de Geografia e Estatística. (2020). Pesquisa Pecuária Municipal. https://sidra.ibge.gov.br/tabela/74

Kottek, M., Grieser, J., Beck, C., Rudolf, B., \& Rubel, F. (2006). World Map of the Köppen-Geiger climate classification updated. Meteorologische Zeitschrift, 15(3), 259-263. 10.1127/0941-2948/2006/0130

Marion Filho, P. J., Fagundes, J. O., \& Schumacher, G. (2011). A produção de leite no Rio Grande do Sul: produtividade, especialização e concentração (1990-2009). Revista de Economia e Agronegócio, 9(2), 233-252. 10.25070/rea.v9i2.185

Marion Filho, P. J., Moura, A. C., Brites, M., \& Lorenzoni, R. K. (2015). Concentração regional e especialização na produção de leite do Rio Grande do Sul (1990 - 2010). Revista Brasileira de Gestão e Desenvolvimento Regional, 11(1), 224-242. https://www.rbgdr.net/revista/index.php/rbgdr/article/view/1616/435

Matos, E. H. S. (2007). Dossiê técnico: criação de codornas. Brasilia: CDT/UnB, 22p. Recuperado de http://www.respostatecnica.org.br/dossietecnico/downloadsDT/MTky

Mendonça, M. O. (2020). Ovos de codorna: nutrição e ambiente influenciam a qualidade da produção. ICCBRAZIL. http://www.iccbrazil.com/ovos-decodorna-nutricao-e-ambiente-influenciam-a-qualidade-da-producao/

Miranda, J. A., Ferreira, T. A., Abreu, L. R., Freitas, G. M., Pires, A. V., \& Silva, M. A. (2013). Estudo da qualidade do ovo e descarte de variáveis em grupos genéticos de codornas utilizando análise multivariada. In: X Simpósio Brasileiro de Melhoramento Animal, Uberaba - MG. Anais... Sertãozinho - SP: SBMA

Monasterio, L., \& Cavalcante, L. R. Fundamentos do pensamento econômico regional. In: Cruz, B. O., Furtado, B. A., Monasterio, L., \& Rodrigues Junior, W. (Org.) (2011). Economia regional e urbana: teorias e métodos com ênfase no Brasil. Brasília: Ipea, 406p.

Mota, A. S. B., Lima, P. M. S., Silva, D. S., Abreu, V. K. G., Freitas, E. R., \& Pereira, A. L. F. (2017). Internal quality of eggs coated with cassava and yam starches. Revista Brasileira de Ciências Agrárias, 12(1), 47-50. 10.5039/AGRARIA.V12I1 A5420

Ottonelli, J., \& Grings, T. C. (2017). Produção de arroz nas microrregiões do Rio Grande do Sul: evolução, especialização e concentração. Desenvolvimento em Questão, 15(49), 230-257. 10.21527/2237-6453.2017.40.230-257

Pasquetti, T. J., Furlan, A. C., \& Marcato, S. M. (2011). Desempenho de codornas de corte alimentadas com rações contendo glicerina bruta, oriunda de 39 gordura animal e óleo vegetal, na fase de 1 a 14 dias de idade. In: Reunião Anual da Sociedade Brasileira de Zootecnia, 48, 2011, Belém. Anais... 2011.

Pastore, S. M., Oliveira, W. P., \& Muniz, J. C. L. (2012). Panorama da coturnicultura no Brasil. Revista Eletrônica Nutritime, 9, $2041-2049$. https://www.nutritime.com.br/arquivos_internos/artigos/180\%20-Panorama\%20da\%20coturnicultura_.pdf

Sarcinelli, M. F., Venturini, K. S., \& Silva L. C. (2007). Características dos ovos (2007). Boletim Técnico, Universidade Federal do Espirito Santo. http://www.agais.com/telomc/b00707_caracteristicas_ovos.pdf

Silva, J. H. V., Jordão Filho, J., Costa, F. G. P., Lacerda, P. B. de, \& Vargas, D. G. V. Exigências nutricionais de codornas. In: XXI Congresso Brasileiro de Zootecnia- ZOOTEC, 21, 2011, Maceió. Anais. Maceió: UFAL, 2011.

Silva, A. F., Sgavioli, S., Domingues, C. H. F., \& Garcia, R. G. (2018). Coturnicultura como alternativa para aumento de renda do pequeno produtor. Arquivos Brasileiro de Medicina Veterinária e Zootecnia, 70(3), 913-920. https://doi.org/10.1590/1678-4162-10065

Silva, L. N., Santos, M. A. S., Rebello, F. K., Bezerra, A. S., \& Martins, C. M. (2019). Comportamento da produção e dos preços de ovos de galinha no estado do Pará, Brasil. Agrarian Academy, 6(12), 113. http://www.conhecer.org.br/Agrarian\%20Academy/2019A/comportamento\%20producao.pdf

Suzigan, W., Furtado, J., Garcia, R., \& Sampaio, S. E. (2003). Coeficientes de Gini locacionais-GL e aplicação à indústria de calçados do Estado de São Paulo. Nova Economia, 13(2), 39-60. https://revistas.face.ufmg.br/index.php/novaeconomia/article/view/415

Suzigan, W., Furtado, J., Garcia, R., \& Sampaio, S. (2004). Cluster e sistemas locais de produção: mapeamento, tipologia e sugestões políticas. Revista de Economia Política, 24(4). 10.1590/0101-35172004-1606

Taco- Tabela Brasileira de Composição de Alimentos. NEPA, Campinas, 2011. http://www.nepa.unicamp.br/taco/tabela.php?ativo=tabela

Zanella, L. C. H. (2013). Metodologia de Pesquisa. (2ª ed.) reimp. - Florianópolis: Departamento de Ciências da Administração/UFSC, 2013.134 p. : il 